\title{
Design of Circular Arc Blade Hydrokinetic Turbine-A Case of Rural Electrification in Zambia
}

\author{
Ackim P. Mvula, Lennox Siwale, Edwin Luwaya \\ Mechanical Department, Copperbelt University, Kitwe, Zambia \\ Email: ackimpmvula@gmail.com
}

How to cite this paper: Mvula, A.P., Siwale, L. and Luwaya, E. (2019) Design of Circular Arc Blade Hydrokinetic Turbine-A Case of Rural Electrification in Zambia. Journal of Power and Energy Engineering, 7, 60-69.

https://doi.org/10.4236/jpee.2019.79004

Received: July 15, 2019

Accepted: September 16, 2019

Published: September 19, 2019

Copyright $\odot 2019$ by author(s) and Scientific Research Publishing Inc. This work is licensed under the Creative Commons Attribution International License (CC BY 4.0).

http://creativecommons.org/licenses/by/4.0/

\begin{abstract}
The rate of electrification in rural areas in Zambia is very low, currently standing at less than $5 \%$ despite having abundant flowing water resources. Hydrokinetic technology is an alternative among other promising technologies for rural area electrification because of availability of abundant flowing Rivers and low population in rural settlement. In this paper, the author designed and numerically simulated a circular arc blade hydrokinetic turbine system. The design power for the horizontal axis hydrokinetic turbine was 3 $\mathrm{kW}$ at water velocity of $3 \mathrm{~m} / \mathrm{s}$ with the tip speed ratio of 2.5 , angle of attack of 10 degrees and power coefficient of 0.4 . In this work, a numerical simulation was employed to characterize and develop the horizontal axis hydrokinetic turbine. The prototype circular arc blade horizontal axis hydrokinetic turbine was tested in one of stream in Zambia and the results were compared with the numerical simulation results.
\end{abstract}

\section{Keywords}

Horizontal Axis Hydrokinetic Turbine, Tip Speed Ratio, Power Coefficient, Circular Arc Profile

\section{Introduction}

The major source of energy for Zambia includes electricity, petroleum, coal, biomass, and renewable energy. The country imports all of its petroleum, but it is also self-sufficient in the other energy resources, because it has good amount of unused reserves of these forms of energy. According to Zambia Development Agency report, it shows that "the country's economy has been growing at an average of 5 percent per annum over the past 10 years and demand for energy has 
also been rising. The demand for the most important energy source in the country-electricity has been growing at an average of about 3 percent per annum mainly due to the increased economic activity in the country especially in the agriculture, manufacturing and mining sectors, as well as increased activity in the region" [1]. Furthermore, the growing economy of the country has also caused an increase in the demand for the other forms of energy resources such as coal and petroleum, as these have got major impact production and operations in most economic sectors. In recent years, the energy market has seen significant growth in the demand for renewable energies as an alternative source of energy, and this has proved that renewable energies are the alternative source in that it is environmental friendly [1].

The International Energy Agency (IEA) and the World Bank, both show that the rate of electrification in Zambia stood at $28 \%$ in 2014. But the survey conducted in 2015 by the government of Zambia shows the figure of $31 \%$. The rate of electrification in rural areas, as it is the case in most developing countries, is currently much lower at 5\% (World Bank) or 4.4\% (Government of Zambia). This shows that at least 10 million people or 2 million households do not have access to electricity [2].

Although Zambia is endowed with abundant energy resources, its rural population access rate to electricity is less than $2 \%$. Access to electricity cannot be overlooked as it provides economic development and it also helps in providing energy for irrigation to Zambian farmers. Despite the high demand for electricity in rural areas to sustain pump irrigation farming, the traditional programs by the national utility Zambia Electric Supply Company (ZESCO) for expanding access to electricity through extending the national grid have thus far failed to give significant improvements. In response, the Zambian Government created the Rural Electrification Authority (REA) to carry out innovative approaches to rural electrification and governs the Rural Electricity Fund (REF) [3]. Despite the efforts in improving the rural electrification, there is little progress and success rates, Rural Electrification Master Plan (REMP) targeted 15\% rural electrification rate by 2013 , but currently, the rural electricity access rate is at $4.4 \%$ for grid power and $7.4 \%$ for solar power [4]. The technologies currently being employed to promote rural electrification in Zambia include Grid Extension, Mini hydro (from $200 \mathrm{~kW}$ to $10 \mathrm{MW}$ ) Development, Solar mini-grids, Solar Home System Installations, Biomass and Biogas and Wind [5].

The success rate of most rural areas electrification projects is very low because power generating project requires a large sum of funding to be implemented hence little or no access to electricity in rural areas.

Most of the rural areas in Zambia are situated near or close to flowing water, thus, making the hydrokinetic technology the most economical and reliable option for generating electric power. According to Kamal A.R. Ismail and Tiago P. Batalha, research reveals that most parts of the world are interested in hydrokinetic turbine technology especially in relation to River application [6]. The hy- 
drokinetic technology works on the principle of converting the kinetic energy of flowing water into rotational energy by turning the rotor coupled to an electric generator which in turn converts rotational energy into electric energy [6]. In order to produce affordable power for rural communities, the manufacturing cost of the hydrokinetic turbine must below. Tao Bian et al. research on flow loss and structure of circular arc blade with different leading edge, where a comparison was made between NACA (National Advisory Committee for Aeronautics) profiles and circular arc blade profiles. The result showed that NACA profiles are able to function and perform better than circular arc blade profile, but the development and production of these profiles are very expensive thus making the circular arc blade profiles an alternative for producing power as their manufacturing cost is very low [7]. Grant Ingram studied wind turbine blade analysis using the blade element momentum method, where Grant showed that for selection of an aero foil for a turbine with the tip speed ratio of less than $3(\lambda<3)$, the curved plate or circular arc blade profile can be used rather than an aero foil [8]. Kamal A.R. Ismail and Tiago P. Batalha carried out a comparative study on river hydrokinetic turbine blade profiles, where four geometries were investigated: NACA 0018 profile, NACA 1548 Asymmetric profile, flat plate and circular arc profile. The numerical simulation results showed that the circular arc profile is more efficient and produce more power [6].

This paper focuses on the description of the steps involved in the design and numerical simulation of a small horizontal axis hydrokinetic turbine (circular arc blade profile), comparing the result to a prototype turbine which was tested in one of the Zambian Rivers as the method for generating electrical power for off-grid rural communities in developing countries.

\section{Methods and Materials}

\subsection{Materials}

The basis for the material selection is centered on three major factors i.e. the bending moment distribution relating to the loads applied on the blades coupled with the turbine operating environment and cost of production. If high bending moments are predicted during operation, then the blade materials should have high specific strength and stiffness for it to retain its shape under high loadings. Since the blade will be immersed in corrosive and erosive water, the current can lead to the material properties being degraded over long periods of time. Thus, the material used should withstand this corrosive and erosive environment while retaining its high strength and stiffness level [9]. In this research, stainless steel was used for the blade with the following mechanical properties as shown in Table 1.

Table 1. Mechanical Properties of the blades [9].

\begin{tabular}{ccccc}
\hline Material & $\begin{array}{c}\text { Young Modulus } \\
(\mathrm{GPa})\end{array}$ & $\begin{array}{c}\text { Density } \\
\left(\mathrm{kg} / \mathrm{m}^{3}\right)\end{array}$ & Poison ratio & $\begin{array}{c}\text { Tensile Strength } \\
\text { Ultimate/Yield (MPa) }\end{array}$ \\
\hline Stainless steel & 193 & 8000 & 0.3 & $400 / 280$ \\
\hline
\end{tabular}




\subsection{Methods}

\subsubsection{Hydrodynamic Blade Design}

The kinetic energy contained in water by mass, $\dot{m}(\mathrm{~m} / \mathrm{s})$ with unidirectional and uniform speed $V_{1}(\mathrm{~m} / \mathrm{s})$, is given by Equation (1).

$$
E=\frac{1}{2} \dot{m} V_{1}^{2}
$$

The mass flow rate through a stationary surface of a control area swept by rotor blade, $A$ ( $A=\pi R^{2}$, where $R$ is the blade radius in (m)), with water density, $\rho\left(997 \mathrm{~kg} / \mathrm{m}^{3}\right.$ at $\left.25^{\circ} \mathrm{C}\right)$ is given by Equation (2).

$$
\dot{m}=\rho A V_{1}
$$

On the other hand, the power extracted from a stream of water is calculated using Equation (3).

$$
P=\frac{1}{2} \rho A V_{1}^{3}
$$

The amount of energy quantity that can be extracted from water, exist in terms of a physical limit and is independent of the design. The amount of energy extraction is maintained in a flow process by reducing the kinetic energy, as a result, the velocity of water reduces. The magnitude of how much energy is harnessed is dependent on the flow speed reduction over the turbine, zero final velocity would imply $100 \%$ extraction and therefore, zero flow. It is difficult to achieve zero flow scenario hence all water kinetic energy may not be used up. The wind turbines efficiency has a maximum limit of $59.3 \%$ which is widely acceptable for wind turbines. This parameter is commonly known as the power coefficient $C_{p}$, where $\max C_{p}=0.593$ referred to as the Betz limit [9]. This scenario is only experienced when the velocity of the water velocity leaving the turbine is one third of velocity entering the turbine.

On the other hand, the quantity of energy that can be extracted from the water by the hydrokinetic turbine is also reduced by the driver train efficiency, $\eta$ (generator, gearing, etc.). The value of $\eta$ is assumed to be $70 \%$, a typical and conservative value for a small turbine for electric generation [10]. Therefore, Equation (3) is modified obtaining Equation (4).

$$
P=\frac{1}{2} \rho A V_{1}^{3} C_{p} \eta
$$

According to Kamal $A$. and Tiago $P$. research, it reveals that seven circular arc blades for different values of tip speed ratio have the maximum power coefficient which occurs at tip speed ratio of 2.5 as shown in Figure 1.

Assuming that $P$ is $3 \mathrm{~kW}$, the water current velocity is $3 \mathrm{~m} / \mathrm{s}, C_{P}$ is 0.4 and $\rho$ is $997 \mathrm{~kg} / \mathrm{m}^{3}$, the radius of the turbine blades can be calculated using Equation (4). The radius of the blade required is equal to $0.253 \mathrm{~m}$. For simplicity, a blade radius of $0.25 \mathrm{~m}$ was used.

\subsubsection{Blade Structural Design}

Various structural configuration for a curved plate were designed and tested in 
ANSYS Fluent but most of the configuration had high flow separation which induced an adverse pressure gradient which greatly reduced the lift force and increased the drag force on the curved blade. The configuration shown in Figure 2 had low flow separation hence, it was considered as the structural configuration for the hydrokinetic turbine for this research.

The blade shown in Figure 2 has an angle of attack of 10 degrees and chord length of $0.31 \mathrm{~m}$ and Figure 3 shows the $3 \mathrm{D}$ model of the turbine with hub length and diameter of $0.5 \mathrm{~m}$ and $0.2 \mathrm{~m}$ respectively.

\subsection{FEM Analysis}

The finite element models (FEM) were developed using the software ANSYS 17.0 academic version through static structural analysis using Mechanical APDL solver. The solid blades and hub of the model had unstructured tetrahedral mesh which converged with 29,427 nodes and 16,489 elements. The hub of the model was treated as a fixed support and all blades were treated as cantilevered beam with all the degrees of freedom being fixed at the hub. The external loads on the

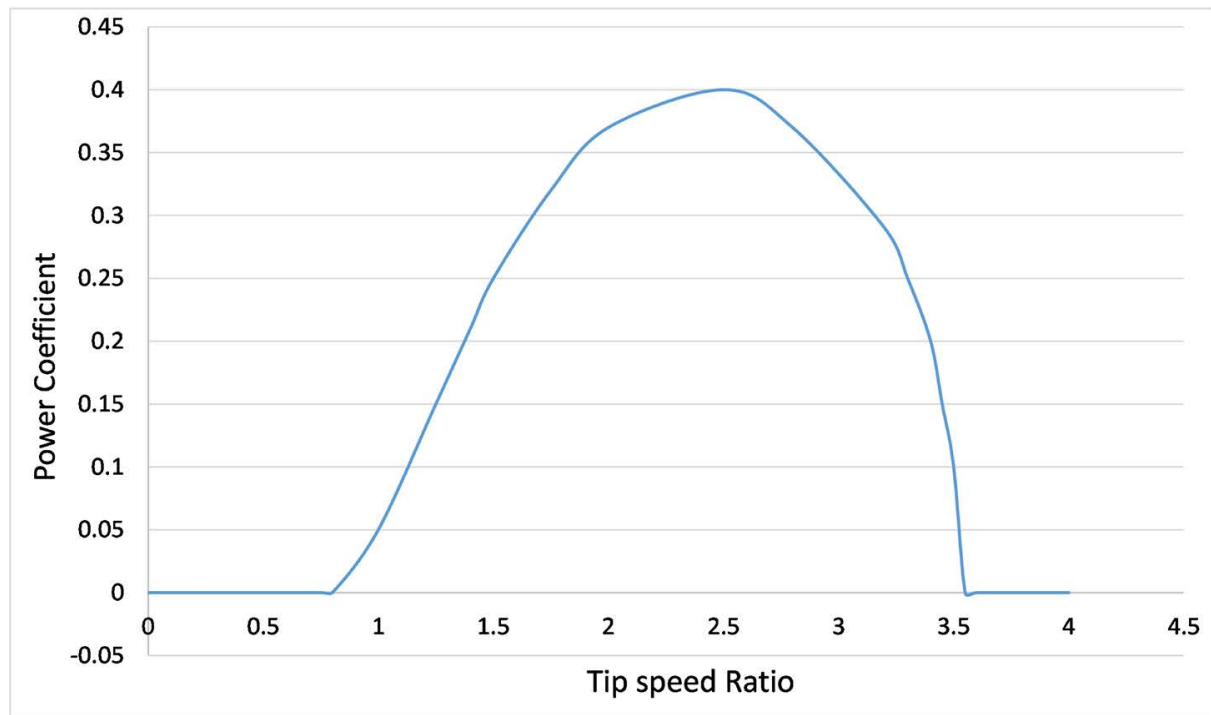

Figure 1. Variation of power coefficient with tip speed ratio [6].

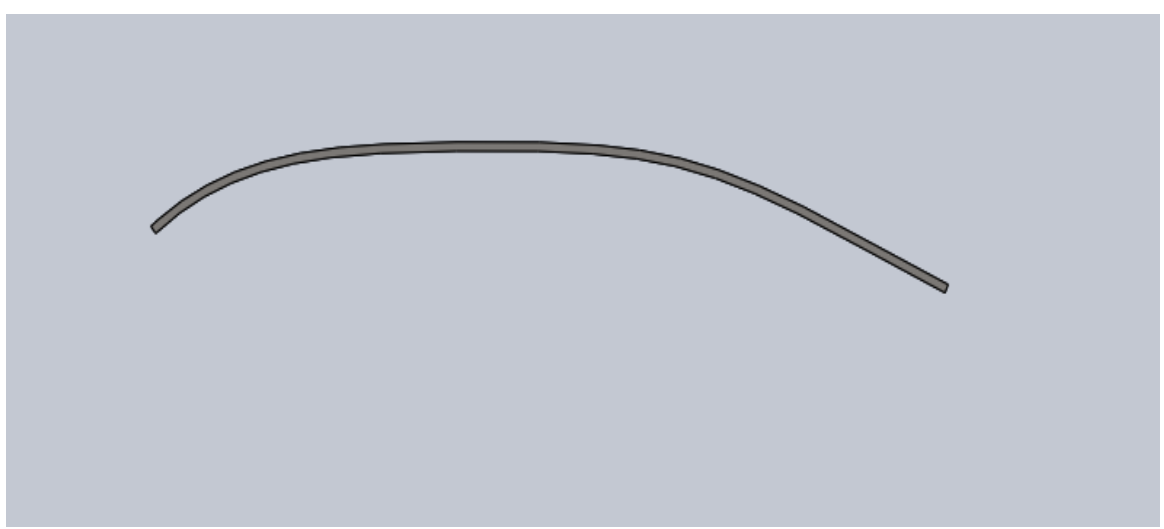

Figure 2. 2D Circular arc blade profile. 
blades: gravitational, centrifugal and hydrodynamic forces were used for structural analysis. The result for the maximum and minimum von-Mises stresses, factor of safety and total deformation (displacements) over the complete blade geometry for different blade thickness are presented in Table 2 .

The blades have high Von-Mises stresses at the rear part near the hub and the deformation is high at the tip of the rear part of the blades as shown in Figure 4(a) and Figure 4(b) respectively.

The stress level for blade thickness $1(\mathrm{~mm})$ exceeded the limit value and the deformation was very high with factor of safety less than 1 . The stress level for blade thickness $2(\mathrm{~mm})$ was lower than the limit value but the deformation was

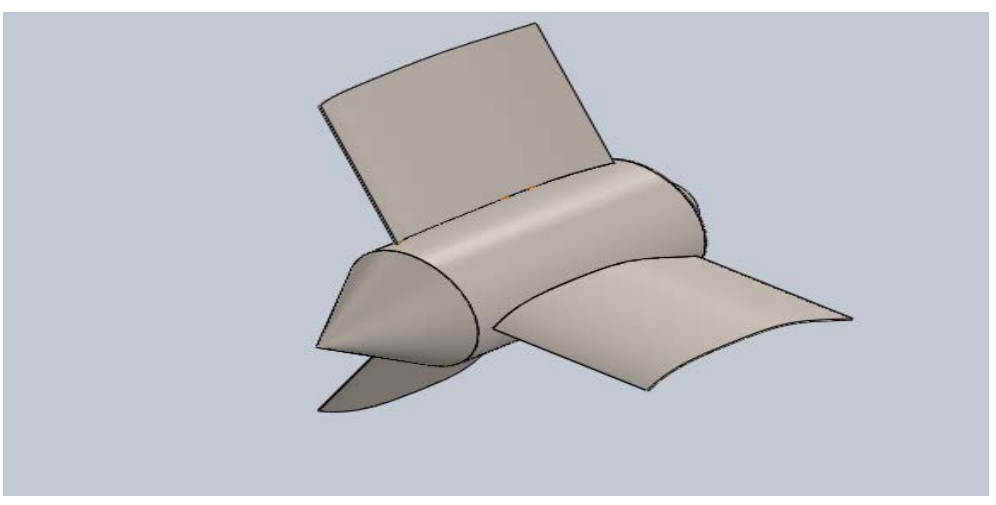

Figure 3. 3D model of the turbine.

Table 2. Structural simulation result of the blade.

\begin{tabular}{|c|c|c|c|c|c|c|}
\hline \multirow{2}{*}{ Material } & \multirow{2}{*}{$\begin{array}{c}\text { Blade } \\
\text { thickness } \\
(\mathrm{mm})\end{array}$} & \multicolumn{2}{|c|}{ Von-Mises Stress (MPa) } & \multicolumn{2}{|c|}{ Factor of Safety } & \multirow{2}{*}{$\begin{array}{c}\text { Total } \\
\text { deformation } \\
(\mathrm{mm})\end{array}$} \\
\hline & & minimum & maximum & minimum & maximum & \\
\hline Stainless Steel & 1 & $4.63 e-5$ & 437.97 & 0.197 & 15 & 10 \\
\hline Stainless Steel & 2 & $1.13 e-5$ & 158.58 & 0.544 & 15 & 2.8 \\
\hline Stainless Steel & 3 & $3.73 e-7$ & 83.96 & 1.5 & 15 & 0.1 \\
\hline
\end{tabular}

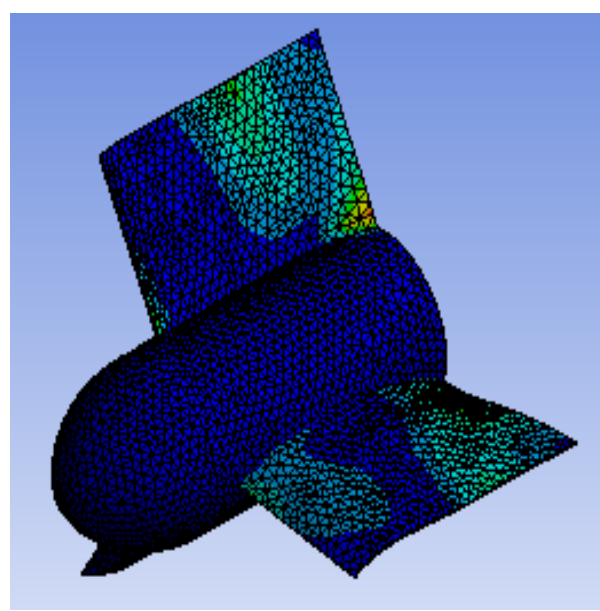

(a)

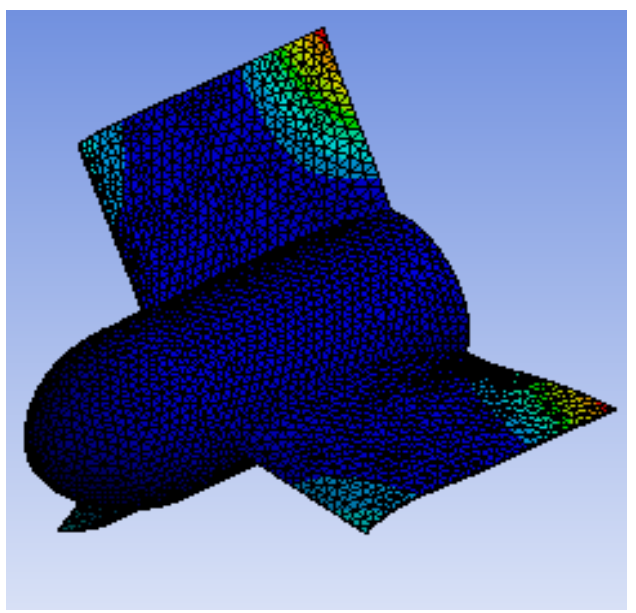

(b)

Figure 4. (a) Von-Mise stress on the table and (b) deformation on the blade. 
still high and factor of safety less than 1 . On the other hand, the stress level for blade thickness $3(\mathrm{~mm})$ was very low and zero deformation with factor of safety greater than 1 . Therefore, the blade thickness of $3(\mathrm{~mm})$ was adopted as the design thickness for the blade as it had high specific strength and stiffness to retain its shape under high loadings.

\section{Results and Discussion}

\subsection{Numerical Simulation of the Circular Arc Profile}

The numerical simulations were realized for a $2 \mathrm{D}$ configuration of the circular arc profile with 10 degrees angle of attack, using Fluent flow in ANSYS 17.0. The converged result was obtained with 26,494 nodes and 17,664 elements.

From Figure 5, the circular arc configuration experiences little flow separation at the tip end of the blade and vortex is encountered in the wake region not on the blade. This eliminates losses of lift force as the effects of adverse pressure gradient on the blade are minimal because of little flow separation on the blade. Figure 6 shows the pressure distribution on the blade, the hydrodynamic forces acting on the concave region of the profile are greater than the hydrodynamic force acting on the convex region, this is confirmed in Figure 7 by static pressure distribution on the blade. This result shows the blade experiences more lift which results in an increased torque on the rotor.

\subsection{Comparison of Experimental Results with Numerical Simulation}

The prototype turbine was tested in the Kabalenga River, Nchelenge district, Luapula

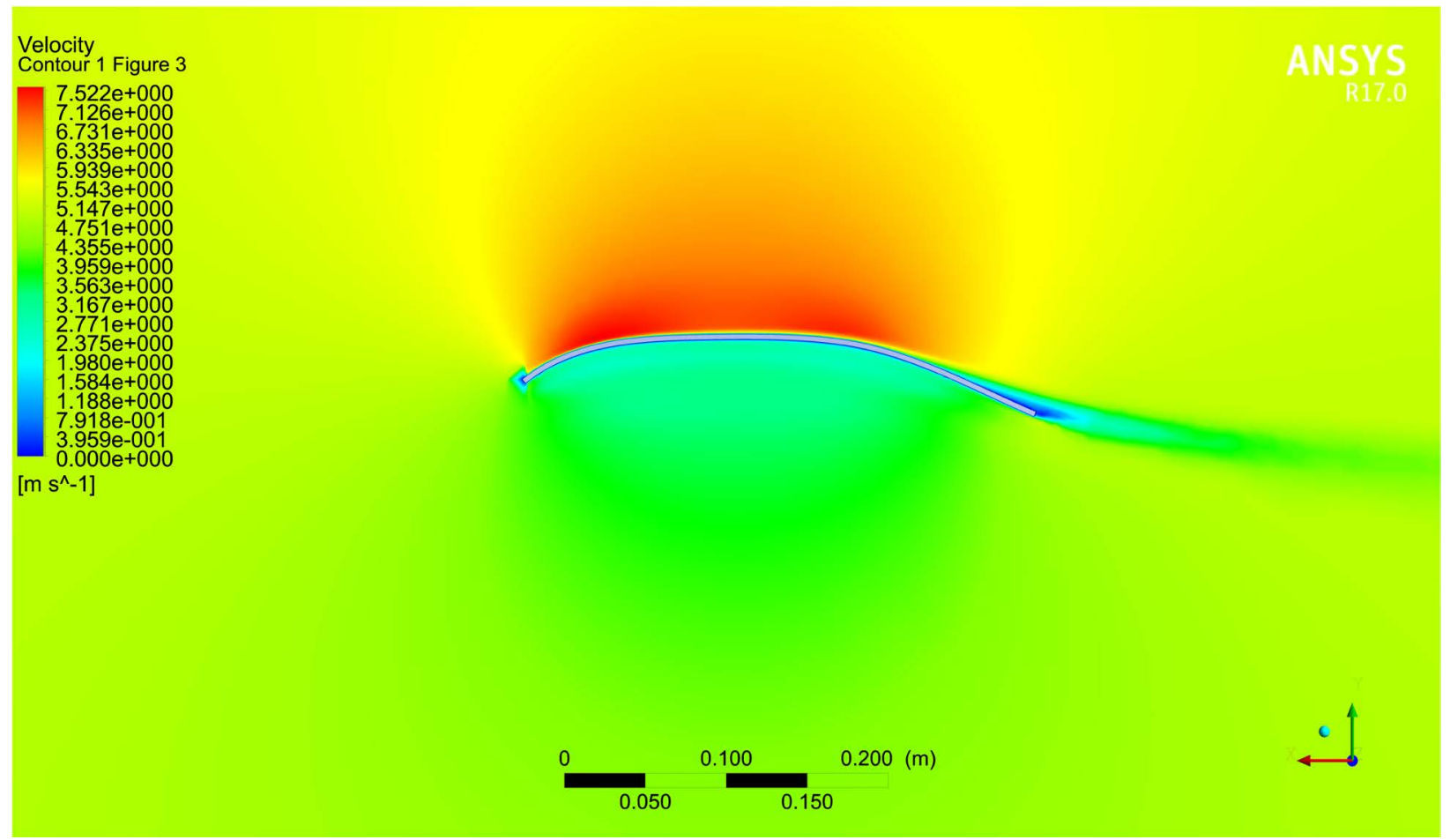

Figure 5. Distribution of velocity for a circular arc profile. 


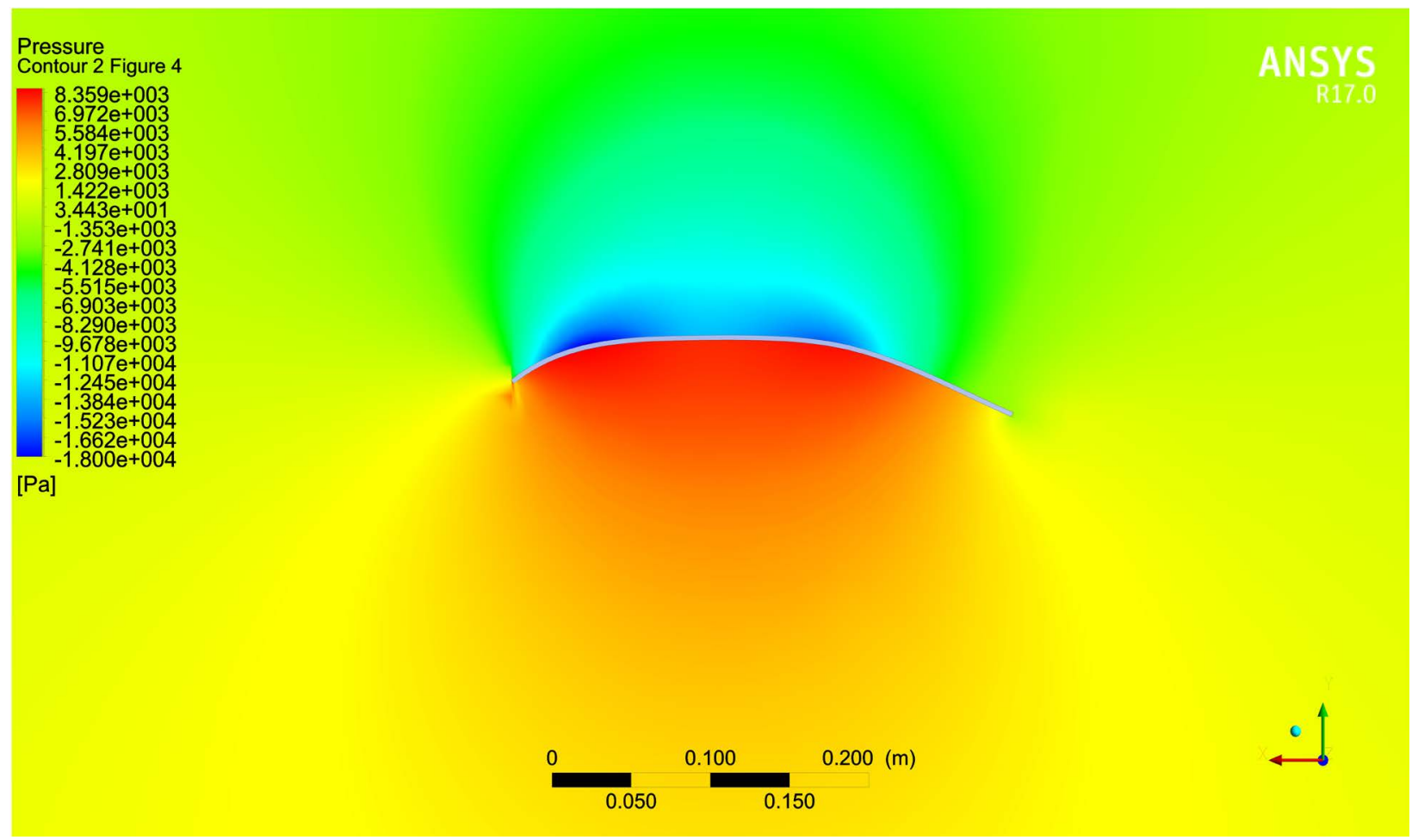

Figure 6. Distribution of pressure for circular arc profile.

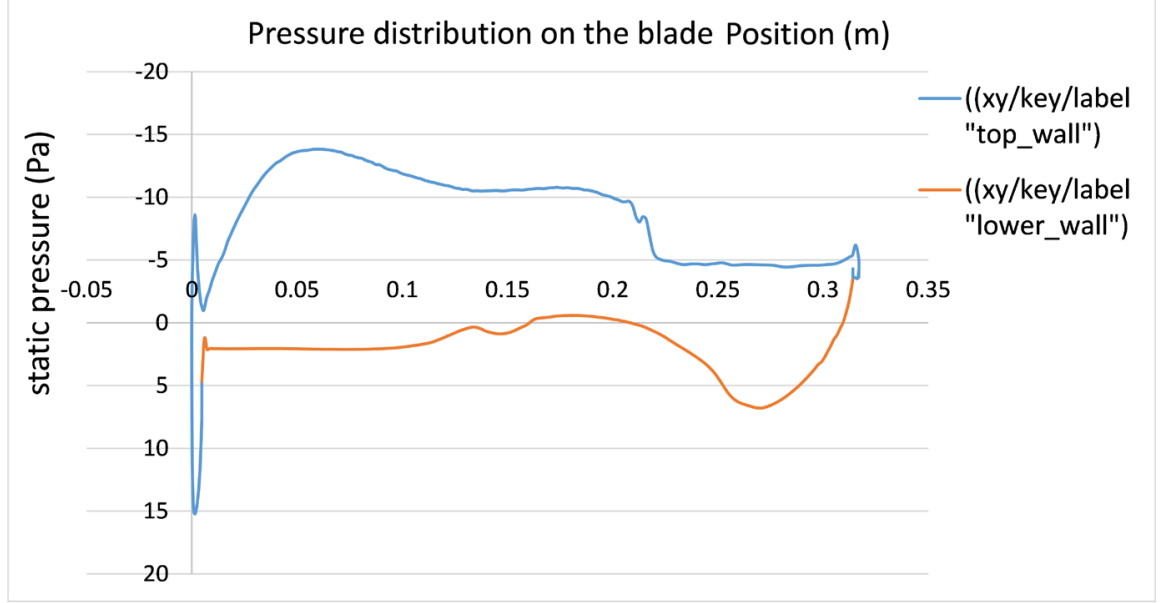

Figure 7. Static pressure distribution on the lower and top part of the blade.

Province at the water velocity of $0.596 \mathrm{~m} / \mathrm{s}$. The measured angular speed on the shaft was $26 \mathrm{rpm}$ and measured torque was $9.81 \mathrm{Nm}$ translating into $26.997 \mathrm{~W}$ power. The numerical simulation of a 3D circular arc blade horizontal axis hydrokinetic turbine model was realized using CFX in ANSYS 17.0. The converged result was obtained at 96,922 nodes and 492,961 elements. Using same flow velocity of $0.596 \mathrm{~m} / \mathrm{s}$ and turbine angular speed of $26 \mathrm{rpm}$, the torque on the rotor from the software was $12.348 \mathrm{Nm}$ and the power output was $33.98 \mathrm{~W}$. Figure 8 shows the variation of torque with flow velocity and Figure 9 shows the variation of power extracted from water with flow velocity. The simulation results 


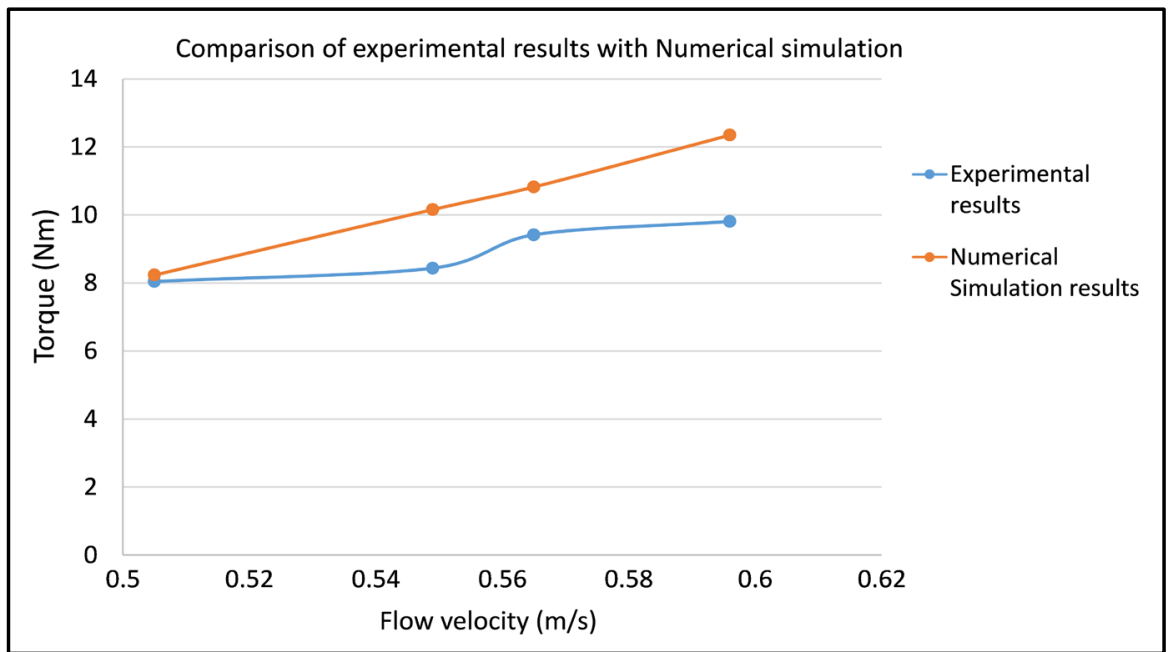

Figure 8. Variation of Torque with flow velocity.

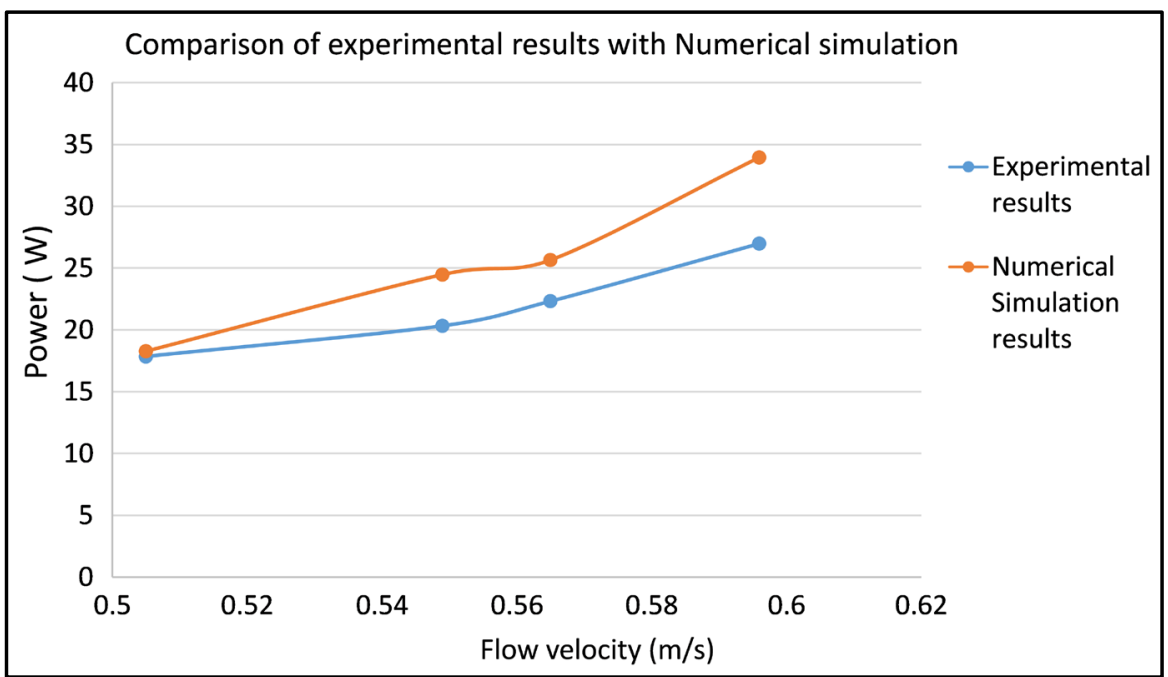

Figure 9. Variation extracted Power with flow velocity.

shows high values of result than experimental results, this could be attributed to the fact the prototypes turbine experienced some friction in the bearings and power transmitting belt hence lower values of the results.

\section{Conclusion}

In conclusion, the work describes the approach to be used in the design of cheap and easy to maintain hydrokinetic turbine for rural areas application. From the numerical simulation and practical result, it is shown that even at low water velocity (i.e. $0.5 \mathrm{~m} / \mathrm{s}$ ), the turbine is capable of generating meaningful power due to blade configuration which generates more lift force and less drag force whereby increasing rotor torque. It was observed that the significant power extraction from the River by the turbine can be achieved by high river flow velocity in the range of $1 \mathrm{~m} / \mathrm{s}$ and above. For deeper rivers, a bigger diameter turbine of same blade profile can be used to extract more hydro-power. 


\section{Acknowledgements}

The author wishes to thank the Africa Development Bank and The Copperbelt University for the research grant.

\section{Conflicts of Interest}

The authors declare no conflicts of interest regarding the publication of this paper.

\section{References}

[1] Zambia Development Agency (2014) Annual Report. 1-15.

[2] Energy Access Africa (2017) Electricity Access in Zambia.

[3] CORE International Inc. (2005) Zambia Rural Electrification Master Plan. Phase 1: Rapid Resource Assessment. Final Report, 70.

[4] Musonda, G. (2017) Status of Rural Electrification in Zambia Presentation. 1-12.

[5] Chilala, A. (2016) Presentation on the DIA Visual Tool Application to Assess Impacts on Projects: Rural Area Authority-Zambia. 1-13.

[6] Ismail, K.A.R. and Batalha, T.P. (2015) A Comparative Study on River Hydrokinetic Turbines Blade Profiles. International Journal of Engineering Research in Africa, $\mathbf{5}$, 1-10. http://www.ijera.com

[7] Bian, T., Han, Q., Sayar, S., Feng, J. and Böhle, M. (2018) Flow Loss and Structure of Circular Arc Blades with Different Leading Edges. Advances in Mechanical Engineering, 10, 1-12. https://doi.org/10.1177/1687814017732895

[8] Ingram, G. (2005) Wind Turbine Blade Analysis Using the Blade Element Momentum Method. Version 1.0 List of Figures. Power, No. c, 1-21.

[9] Chica, E., Pérez, F. and Rubio-Clemente, A. (2016) Rotor Structural Design of a Hydrokinetic Turbine. International Journal of Applied Engineering Research, 11, 2890-2897.

[10] Khan, M.J., Iqbal, M.T. and Quaicoe, J.E. (2008) River Current Energy Conversion Systems: Progress, Prospects and Challenges. Renewable \& Sustainable Energy Reviews, 12, 2177-2193. https://doi.org/10.1016/j.rser.2007.04.016

\section{Nomenclature}

$$
\begin{aligned}
& \text { ZESCO-Zambia Electricity Supply Company } \\
& \text { IEA-International Energy Agency } \\
& \text { REA-Rural Electrification Authority } \\
& \text { NACA-National Advisory Committee for Aeronautics } \\
& \text { FEM-Finite Element Method } \\
& \lambda-\text { Tip Speed Ratio } \\
& \eta \text {-Drive Chain Efficiency } \\
& C_{p}-\text { Turbine Power Coefficient }
\end{aligned}
$$

